\title{
O DESENVOLVIMENTO DE ELEMENTOS DE PROTEÇÃO DE FACHADA RESPONSIVOS - EXPLORAÇÃO E CONTROLE DE UM PROCESSO
}

Development of a responsive system for building façade protection exploring and controlling a process

Carlos Eduardo Verzola Vaz', Joana Pack Melo Sousa, Hugo Rodrigues de Souza Pinto $^{2}$, Adriano Rodrigo Barreto Cardoso ${ }^{2}$, Natalia Queiroz ${ }^{3}$

RESUMO: Este artigo tem como objetivo apresentar um processo exploratório de pesquisa para a integração de ferramentas e técnicas visando a criação de elementos de proteçào de fachada. Como será visto neste documento, o cobogó foi utilizado como referência para o desenvolvimento de um protótipo físico funcional. Este elemento foi criado por dois comerciantes e um engenheiro radicados no Recife no início do século XX - Coimbra, Boeckmann e Góes. O Cobogó apresenta como características básicas o modo de produção seriado, a capacidade de proteger ambientes internos da luz direta do sol e de promover a adequada ventilação destes espaços, a possibilidade de, mesmo sendo um elemento vazado, permitir a sensação de privacidade e, além disso, funcionar como um elemento compositivo na fachada das edificações. O trabalho irá apresentar as diferentes etapas da pesquisa que envolveram, a coleta de dados sobre o uso do Cobogó na cidade do Recife, o processo de desenvolvimento de um conceito geométrico, a elaboração dos diferentes protótipos físicos e digitais e as demais metodologias e softwares utilizados no processo de trabalho.

PALAVRAS-CHAVE: Proteção de fachadas; Cobogó; Arquitetura responsiva.

ABSTRACT: The aim of this paper is present an exploratory research process to integrate technichs and tools to develop a system for building protection façade using as reference the Cobogó. Two traders and one engineer -Coimbra, Boeckmann and Góes - settled in Recife created this element in the early XIX. The Cobogó has as main characteristics the capacity of been manufactured in a mass production system, the capacity of protecting indoor environment from direct sun light and promote natural ventilation in these spaces, the possibility of, even being a hollow element, create a sensation of privacy and, furthermore, be used as a composition element in building façades. This document will present the research different steps, which involved collecting data about how the Cobogó has been used in different buildings in the city of Recife, the genesis of a geometric concept, the development of different physical and digital prototypes and other methodologies and software used along the research.

KEYWORDS: Façade protection; Cobogó; Responsive architecture. 


\section{INTRODUÇÃO}

Segundo Achten (2014) os edifícios responsivos podem ser definidos como aqueles que inteligentemente reagem ao ambiente, as necessidades dos usuários e as condições em seus ambientes internos. Tais estruturas são definidas a partir de diferentes denominações que apresentam pequenas variações de significado: sistemas de automação do edifício, casas inteligentes, edifícios sensíveis, adaptativos, dinâmicos ou interativos, arquitetura cinética, etc. Não há, segundo os autores, um acordo comum em relação à definição de uma categorização e, aparentemente, os termos gravitam entorno de um conjunto de tecnologias e as diferentes distinções estão relacionadas às influências causadas pelos avanços tecnológicos.

Fortmeyer e Linn (2014), afirmam que entre os componentes das edificações com a capacidade de responder automaticamente ao ambiente estão os envelopes ativos ou peles de alta performance. Estes elementos têm a capacidade de responder às condições ambientais, tanto externas quanto internas, funcionando como um meio para a transferência de energia. A origem destes sistemas remete à busca pelo homem de controlar a transferência de energia e o desejo em eliminar as barreiras entre o ambiente construído e o ar fresco e a luz natural do ambiente externo, sem sacrificar o conforto.

Historicamente, exemplos de estratégias com o objetivo de tornar a transição entre o ambiente externo e o interno podem ser identificados em painéis de portas e janelas chinesas (DYE, 1974; STINY, 1977), em painéis Muxarabis islâmicos (TALIB, 1983) ou no brise soleil e Cobogó (GUTIERREZ e LABAKI, 2005), amplamente utilizados na arquitetura moderna (SOUZA, 2012).

Fortmeyer e Linn (2014) também ressaltam que muitos arquitetos que buscam soluções relacionadas ao aprimoramento da troca de energia em fachadas, priorizando o conforto, racionalizaram este conhecimento em uma arquitetura que é dinamicamente responsiva ao lugar, ao clima e aos ocupantes, sem sacrificar os legados formais, materiais e históricos que definem a Arquitetura contemporânea. Recentemente, baseados nesta tradição, arquitetos propuseram investigações mais radicais sobre energia e conforto tirando proveito das novas tecnologias.

A fachada dinâmica do edifício do Instituto do Mundo Árabe, projetada por Jean Nouvel, pode ser citada como um dos primeiros exemplos de impacto que tiram proveito da movimentação de suas partes para controlar o fluxo de energia entre ambientes internos e externos. A fachada sudoeste do edifício é uma parede cintilante de vidro formada por 240 painéis foto sensíveis que se abrem e fecham automaticamente com o objetivo de modular a luz do dia e o ganho de calor solar. Neste caso, pela primeira vez, um edifício usa uma linguagem de projeto tradicional - brise soil em formato de padrões árabes - mas de uma maneira completamente diferente e dinâmica.

Não tão dinâmicas, mas também responsivas eram as soluções tradicionais. O cobogó, por exemplo, pode ser considerado como sendo uma resposta ao problema da ventilação, principalmente em locais de clima quente e úmido. Foi amplamente utilizado na arquitetura moderna, contudo, as possibilidades geradas pelo acesso às tecnologias de condicionamento de ar tornaram este sistema incapaz de competir com o nível de conforto que se busca hoje. Muitas vezes, como será visto neste texto, este é substituído por sistemas mecanizados de condicionamento de ar, a solução mais rápida e simples para se climatizar os ambientes.

Este artigo tem como objetivo apresentar os resultados de um estudo exploratório, visando a integração de ferramentas e técnicas para a criação de elementos de proteção de fachada. Como será visto neste documento, o cobogó foi utilizado como referência para o desenvolvimento de um protótipo físico funcional de um anteparo de proteção responsivo a parâmetros ambientais e a fatores humanos. 
Estes componentes funcionam em grupos independentes, possibilitando assim o direcionamento do vento ou o aumento e redução da iluminação segundo a função exercida em um determinado ambiente. Além de visar a melhoria da performance em relação ao conforto, o sistema reproduz três das características básicas deste sistema de proteção: a capacidade de resguardar os ambientes internos de olhares externos, a possibilidade de serem produzidos em série e a aptidão em produzir diferentes texturas na fachada das edificações, funcionando como componente compositivo.

$\mathrm{O}$ trabalho de pesquisa se desenvolveu em duas fases. Na primeira delas foram analisados vários exemplos de fachadas responsivas, podendo destacar que existem dois tipos de sistemas: os que funcionam com uso de energia externa, e os que se modificam pelas propriedades intrínsecas ao material. A segunda fase da pesquisa relaciona-se ao desenvolvimento do protótipo em si e foi dividida em quatros etapas. A primeira envolveu, por meio de um processo exploratório, a definição de um conceito norteador para a geometria do protótipo, o estudo da movimentação das partes do sistema e de diferentes atuadores que possibilitariam este deslocamento. Nesta etapa foram estudados princípios de dobragem e de deformação de materiais a partir da elaboração de maquetes físicas ou modelos paramétricos. Na segunda etapa os modelos paramétricos foram testados a partir de diferentes aplicativos de simulação e conforto ambiental. Na terceira etapa uma correlação entre sensores e modelo paramétrico foi realizada com o objetivo de testar algoritmos para a implementação da etapa final, que envolvia o desenvolvimento de um protótipo funcional. A quarta e última fase envolveu a elaboração de um protótipo físico funcional.

Durante todas as etapas da pesquisa foi utilizada uma estratégia exploratória, com objetivo de se mapear e testar as diferentes ferramentas que possibilitariam se obter um protótipo físico e, posteriormente, realizar uma análise do comportamento do cobogó "inteligente". Como resultado, este artigo não apresenta conclusões em relação à eficiência do protótipo em si, mas mostra um caminho para que outros pesquisadores desenvolvam trabalhos com objetivos semelhantes. A Figura 1 mostra as etapas da pesquisa, fazendo uma correlação com as diferentes ferramentas utilizadas no trabalho.
Figura 1: Etapas de desenvolvimento do protótipo e as diferentes ferramentas utilizadas. Fonte: Elaboração própria

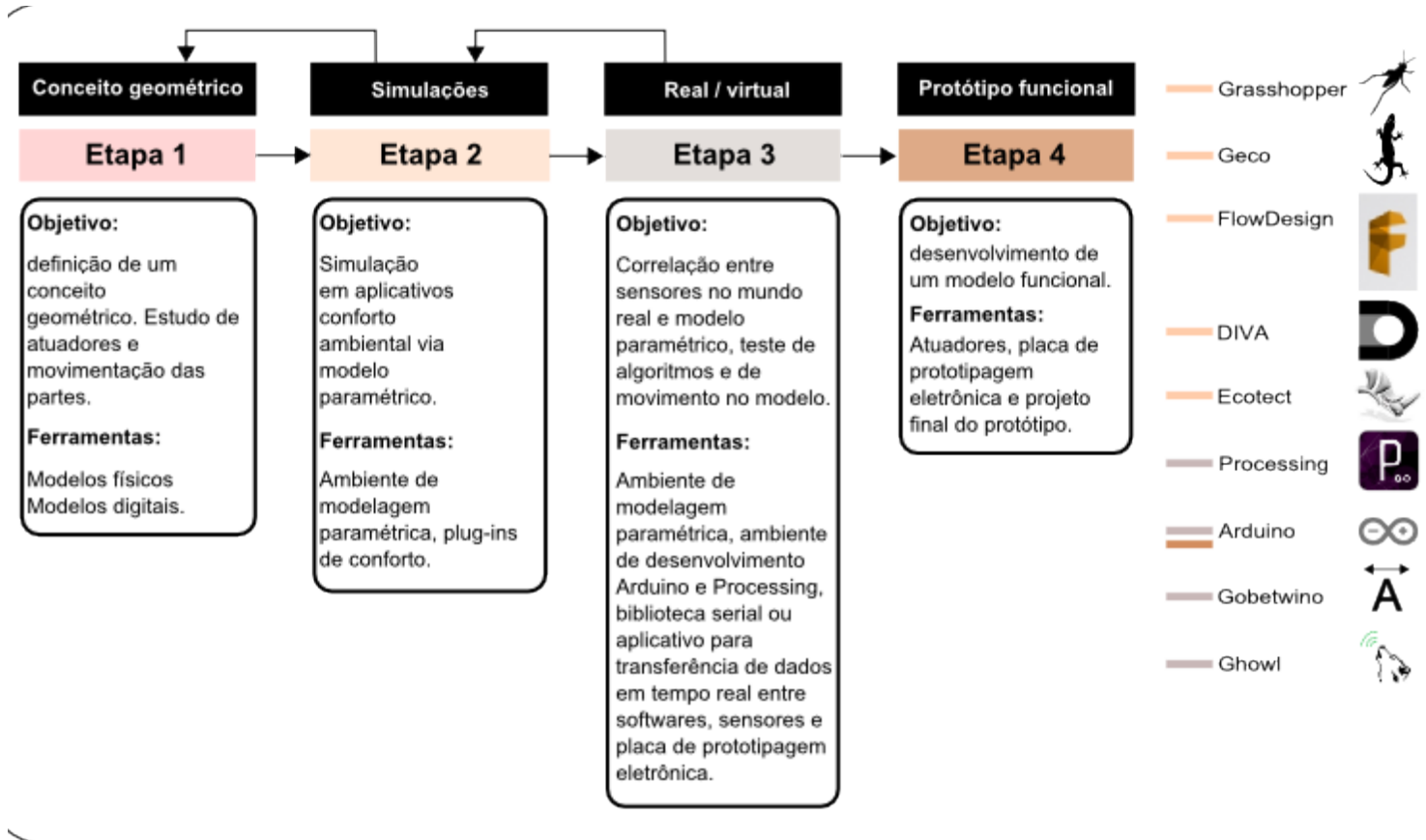




\section{SISTEMAS DE PROTEÇÃO DE FACHADA - DO COBOGÓ AOS SISTEMAS RESPONSIVOS}

Segundo Vieira, Borba e Rodrigues (2012), o Cobogó foi inventado por dois comerciantes e um engenheiro radicados no Recife no início do século XX - Coimbra, Boeckmann e Góes. Seu nome foi dado a partir das iniciais dos sobrenomes de seus inventores e foi inicialmente concebido como um simples elemento pré-fabricado, próprio para ser construído em série, baseado em uma retícula vazada sobre uma placa prismática de concreto. Conforme os autores, na prática, se utilizado como elemento de composição de septos verticais, o elemento permite a passagem da ventilação natural, ao mesmo tempo em que reduz a incidência da luz solar, características que os adequam para projetos em lugares de clima quente e úmido.

Segundo Oliveira (2013), o Cobogó tem função semelhante à dos antigos muxarabi de madeira, também resgatados pela arquitetura moderna. Estes podem funcionar como filtros solares e visuais, apresentando assim atributos semelhantes aos ripados de madeira, porém com a vantagem de possibilitar a criação de grandes planos leves e permeáveis. Um dos primeiros exemplos do uso do Cobogó pode ser identificado na Caixa d'água de Olinda, projetada pelo arquiteto Luiz Nunes, em 1936. Oliveira (2013) afirma que apesar da volumetria da edificação, de geometria simples, contrastar com o ambiente urbano em que foi construída, a obra teve destaque no número especial sobre o Brasil da revista inglesa The Architectural Review, em 1944, como representante de um diálogo entre tradição e modernidade. Vieira et. al. (2012) explicam que o Cobogó, na caixa d’água de Olinda, foi utilizado com a função de "quebra-sol”, que auxiliava na amenização do calor, que incide nas tubulações, preservando e resfriando também a temperatura das águas acumuladas nos tanques superiores.

Assim como o brise soilel, o Cobogó foi largamente utilizado na construção civil durante o século XX, sendo possível identificar sua presença em obras que podem ser consideradas referências da arquitetura brasileira. Atualmente, apesar deste elemento construtivo ainda estar presente em diversas edificações, este tem sido gradativamente substituído pelos sistemas de ar condicionado, que apresentam um alto grau de consumo energético. Em Recife, por exemplo, em inúmeras situações pode se observar a perda da funcionalidade ou a sua substituição. Mesmo em edifícios mais antigos, sistemas de ar condicionado foram adicionados, complementando o conforto em ambientes internos (Figura 2).

Na mesma cidade, é possível verificar que os novos edifícios raramente contemplam o uso do Cobogó como estratégia passiva de projeto, sendo que o ar-condicionado passou a ser utilizado como principal instrumento parar gerar conforto em ambientes internos. Esta situação reflete no desprezo em relação à implantação das edificações e a ausência de preocupação com as fachadas. Em alguns casos ainda se observa o emprego do Cobogó, contudo não diretamente relacionada ao conforto e proteção dos ambientes, mas para a criação de uma segunda pele, com uma textura diferenciada, contemplando aspectos relacionados à estética das edificações.

Apesar de em Recife, em diferentes situações não se observar estratégias adequadas de proteção de ambientes internos, atualmente há uma crescente preocupação com questões relacionadas à sustentabilidade das edificações, o que tem promovido cada vez mais pesquisas que visam identificar soluções alternativas que possibilitem a redução do consumo energético ao longo da vida útil do edifício.

\section{Sistemas responsivos baseados na automação}

Uma das estratégias exploradas por inúmeros projetistas envolve a aplicação de princípios de automação com o objetivo de criar edifícios que respondam a diferentes estímulos ambientais. Este conceito tem origem no trabalho de Negroponte (1975), que descreve a arquitetura responsiva como 
sendo o produto natural da integração da computação com a arquitetura para a produção de espaços ou estruturas otimizadas. Segundo o autor, o início de pesquisas na área foi um reflexo da crise na arquitetura racionalista e da interminável repetição de formas da arquitetura industrializada. O objetivo era criar espaços mais “inteligentes” que respondessem às diferentes exigências dos usuários.

Em diferentes projetos arquitetônicos é possível identificar soluções baseadas na automação do edifício ou de suas partes para promover a adequada insolação e permitir a otimização de processos de ventilação. D’alecon (2013), define as fachadas inteligentes ou responsivas como aquelas que têm a capacidade de se adaptar às condições do ambiente, graças a um sistema que integra dados sobre a performance do edifício, uma modelagem ou avaliação deste desempenho e sistemas de controle permanente para corrigir e adequar o ambiente construído ao clima e uso. Segundo o autor, os elementos típicos que fazem parte dessas estratégias são: a regulagem da iluminação natural e artificial, segundo condições de nebulosidade e de calefação, e de refrigeração, segundo a ocupação dos ambientes.

Tanto o SDU Campus Kolding na Dinamarca, projetado pelo escritório de Henning Larsen Architects, quanto as Torres Al Bahar, em Abu Dhabi projetadas pelos arquitetos do escritório Aedas, contém uma segunda película na fachada que responde a estímulos climáticos. O primeiro é formado por 1600 painéis triangulares perfurados basculantes, enquanto o segundo foi projetado com inspiração cultural no muxarabi (FRANCO, 2013). Ambos possuem um sistema inovador de sombreamento dinâmico, que se auto-ajusta de acordo com o ângulo de incidência e intensidade dos raios solares. As fachadas responsivas têm um conjunto de sensores que determinam a regulação individual e automática de cada painel, permitindo a manutenção das condições de conforto no interior do edifício (SDU, 2015). O edifício Bad Gleichenberg, projetado por Ernst Giselbrecht and Partner ZT GmbH, construído na Áustria em 2007, também introduz um sistema de fachadas dinâmicas que podem ser adaptados às necessidades dos usuários (LOMHOLT, 2008). O grupo DesignInc projetou em 2006 o prédio da prefeitura de Melbourne o CH2 (Council House 2) com o objetivo de o tornar o prédio mais sustentável da Austrália. Um dos elementos considerados no projeto foi o desenho de uma fachada de painéis de madeira automatizados que se adaptam ao longo das quatro estações do ano (MARCON, 2013).
Figura 2: Imagens extraídas de Vieira et. al. (2012) mostrando em detalhe o uso do Cobogó em edificações de substancial valor arquitetônico na cidade do Recife; (2) Situações em que o ar-condicionado passou a ser utilizado como principal instrumento para adequar ambientes internos. Na imagem à esquerda verifica-se que o Cobogó foi retirado em parte da fachada original; (3) Edifícios residências padrões da cidade. Neste caso é possível observar o corriqueiro o uso de elementos vazados; (4) Edificações contemporâneas, com o mesmo projeto, seguindo diferentes orientações no terreno. Fonte: elaboração própria.
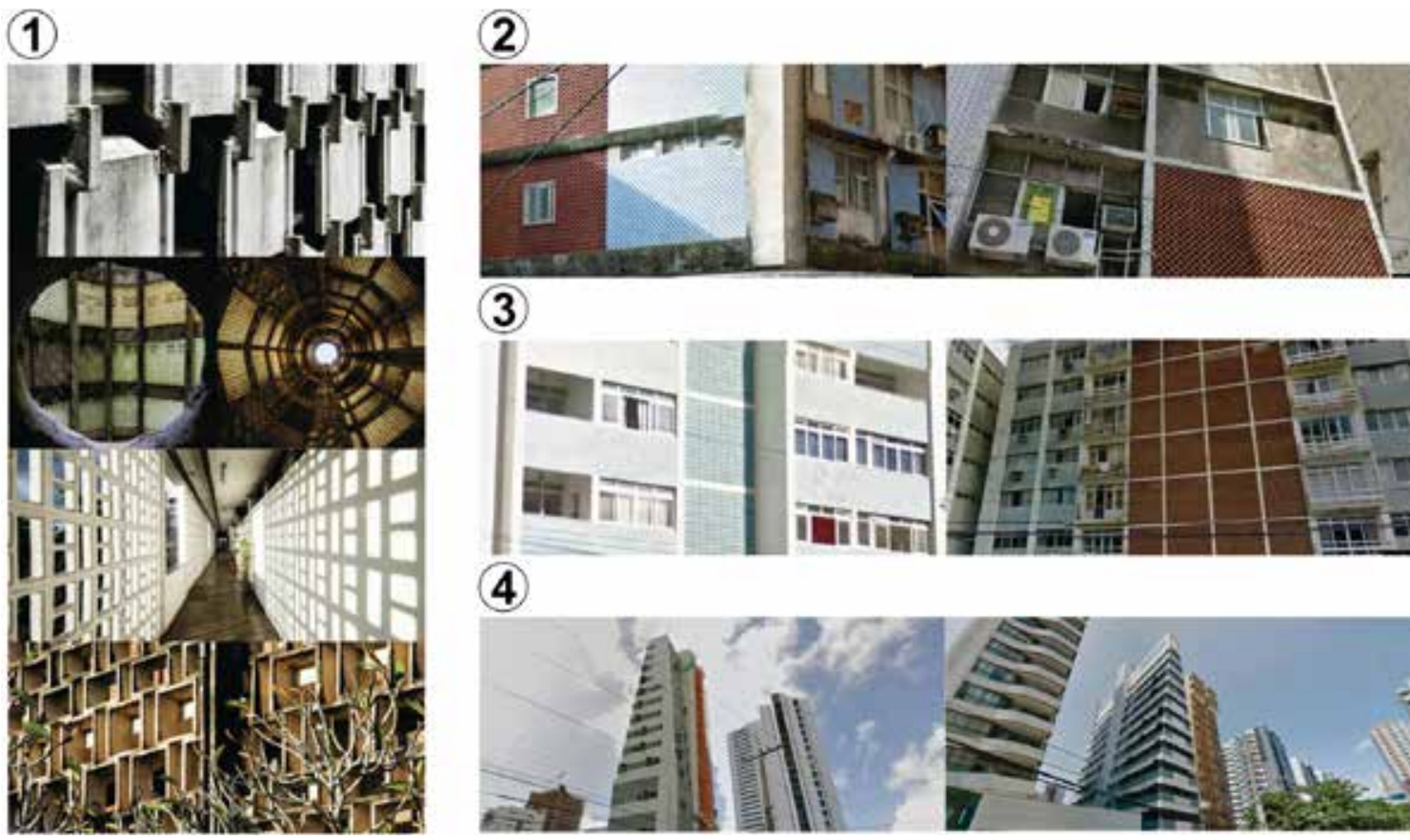


\section{Sistemas responsivos baseados nos materiais inteligentes}

Outra abordagem para o desenvolvimento de sistemas de fachadas responsivas relaciona-se ao uso de materiais inteligentes. Segundo Addington e Schodek (2005), este tipo de sistema incorpora funções tecnológicas permitindo respostas ao ambiente por meio de mudanças em suas propriedades internas ou por meio da ação externa. Os autores definem materiais inteligentes como sendo aqueles que respondem ao ambiente em tempo real, segundo diferentes estímulos. Uma de suas características mais relevantes é sua habilidade em transformar suas propriedades físicas e formais sem requerer uma fonte externa de energia. Os experimentos de cobertura responsiva desenvolvidos pela arquiteta Dóris Sue podem ser citados como exemplo de aplicação destes princípios. Muitos de seus trabalhos envolvem o uso de lâminas com duas camadas de metais com diferentes coeficientes de dilatação. Isto permite que a alteração na temperatura expanda os materiais de forma diferente. Neste caso, a

Figura 3: (1) SDU Campus Kolding; (2) Torres Al Bahar; (3) Bad Gleichenberg; (4) Council House 2. Fonte: (1) SDU, 2015; (2) Franco (2013); (3) Lomholt (2008); (4) Marcon (2013). arquiteta faz uso de peles metálicas que apresentam a capacidade de abrir seus poros, dependendo da temperatura ambiental.

Outro exemplo da utilização de materiais inteligentes pode ser identificado na Air Flow(er) (Figura 4). Este é um sistema independente de energia ativado por meio de variações térmicas, criado pelo escritório Lift Architects. Seu funcionamento se baseia nas pétalas de uma flor de Crocus que se abrem quando expostas a temperaturas mais elevadas.

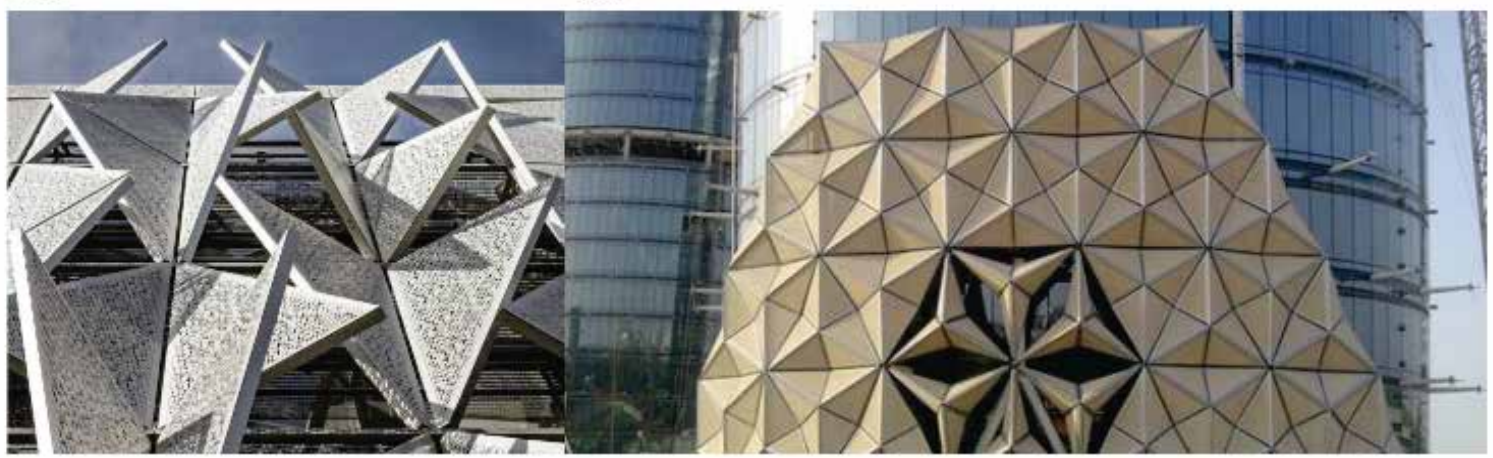

(3)

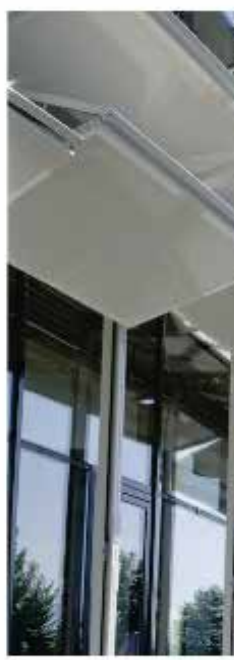

(4)

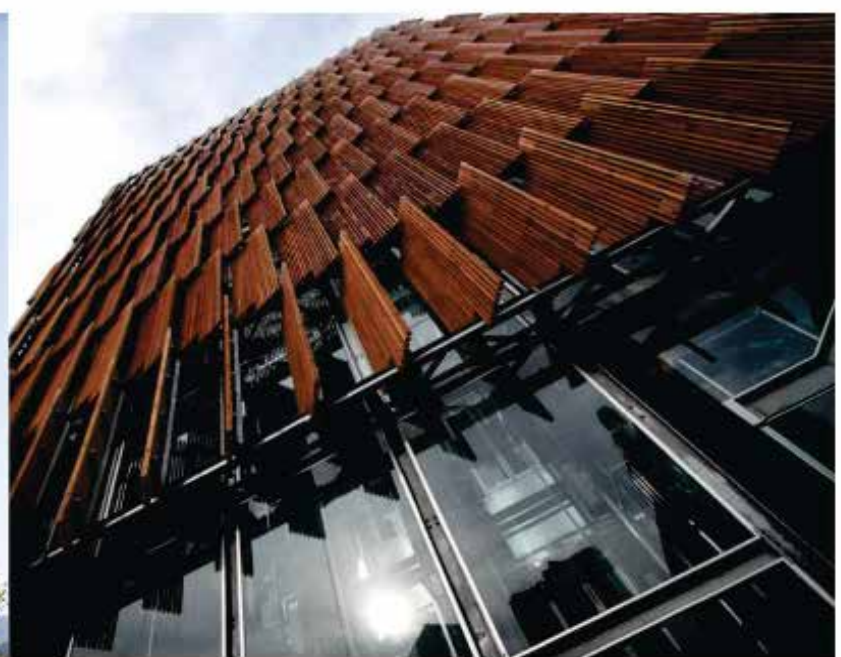


(1)

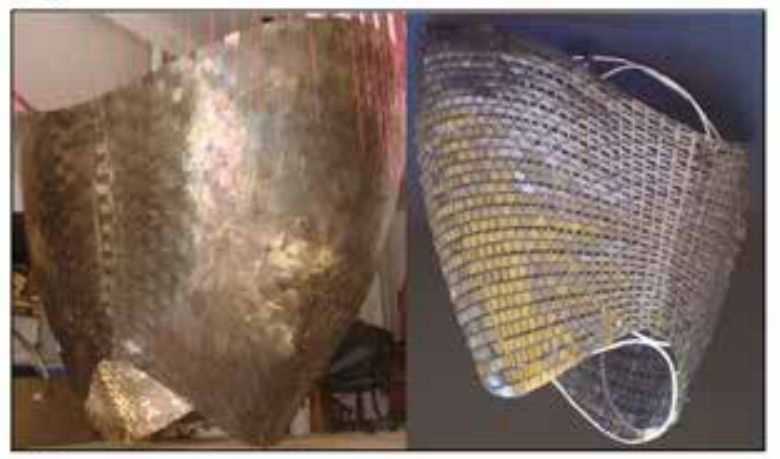

(2)

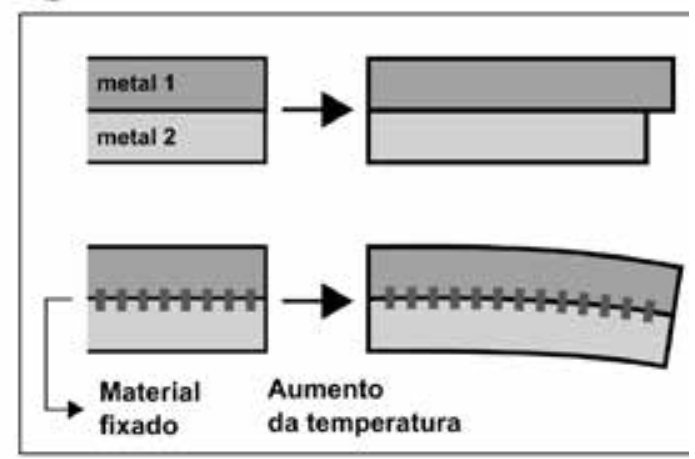

(3)
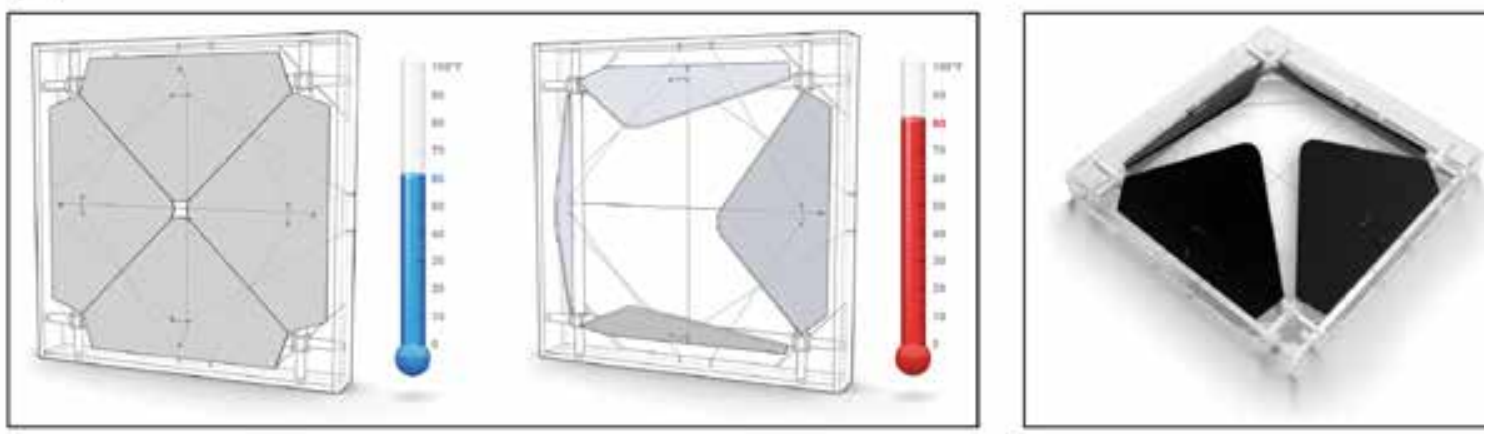

O componente ativo neste caso é um cabo manufaturado com efeito térmico de memória, responsável por movimentar as partes móveis do sistema. Há assim, uma clara diferença em relação às superfícies criadas por Doris Sung, que é materializada com o próprio material responsivo.

Addington e Schodek (2005) também ressaltam que estes sistemas inteligentes respondem basicamente a uma série de condições climáticas e sistemas mais complexos deveriam também acomodar uma maior variedade de condições e critérios de performance, tais como a capacidade de responder a estímulos e necessidades dos usuários e aprender ao longo do tempo.

\section{DESENVOLVIMENTO DE UM PROTÓTIPO}

\section{Definição de um conceito geométrico a partir de modelos físicos e digitais}

Nesta etapa da pesquisa foram definidas as possíveis características geométricas e funcionais que o protótipo deveria ter, fazendo uma correlação com o clima da cidade do Recife, local em que o Cobogó foi inventado. 0 clima da cidade é caracterizado por ser tropical litorâneo quente e úmido, com temperaturas elevadas ao longo do dia e do ano (média anual de $25,5^{\circ} \mathrm{C}$ ), com uma radiação difusa muito intensa, um alto grau de umidade do ar (média de $80 \%$ ) e uma precipitação média anual elevada, sobretudo nos meses de inverno, acima de 2.000mm (FREITAS, 2008). Existem dois padrões climáticos durante o ano: a estação seca ou de estiagem, que se prolonga de setembro a fevereiro (primavera-verão), e a estação chuvosa, de março a agosto (outono-inverno) (BARROS E LOMBARDO, 2013).

A cidade está sob a influência dos ventos alísios do hemisfério austral, com a direção predominante de sudeste e direções secundárias de Sul e de
Figura 4: (1) Estrutura projetada com "materiais inteligentes" pela arquiteta Doris Sung; (2) Diagrama ilustrando a dilatação em lâminas de metal; (3) Elemento de proteção de fachada desenvolvido pela Lift Architects. Fonte: (1) Dewidar, Mohamed e Ashour (2013); (2) Elaboração própria; (3) LIFT ARCHITECTS (2016). 
Leste. A velocidade média, segundo o Instituto Nacional de Meteorologia (INMET), é de 2,82 m/s. Como resultado, o protótipo deverá ter as seguintes características:

(1) Funções básicas: assim como o Cobogó original deve permear a ventilação natural e funcionar como anteparo de proteção da fachada;

(2) Responsivo à luz: Suas partes devem ser móveis, permitindo assim o controle pelo usuário, segundo as necessidades de luz em relação às atividades a serem desenvolvidas nos ambientes;

(3) Responsivo ao vento: em panos de fachada maior, grupos de componentes devem trabalhar num sistema independente, de modo a possibilitar o direcionamento do vento para diferentes áreas dos ambientes.

(4) Padrões de desenho: os componentes devem gerar diferentes configurações na fachada, permitindo variar a composição do edifício.

A partir destas diretrizes, definiu-se que a geometria do componente e a forma com que se daria a movimentação de suas partes deveriam ser definidas segundo a correlação entre as diferentes possibilidades de configuração do elemento, de modo isolado, e com estes trabalhando em diferentes grupos. Além disso, o sistema deveria ser controlado de modo a permitir diferentes configurações em relação à ventilação, à presença ou não de luz direta, ou a parâmetros relacionados a umidade e temperatura. Como resultado, inicialmente foram definidos como parâmetros ambientais a serem coletados pelo sistema: a temperatura, a umidade, e a luminosidade.

O primeiro método explorado durante a elaboração dos protótipos geométricos foi o Miura Fold (NISHIYAMA, 2012). Este sistema de dobragem foi desenvolvido pelo astrofísico japonês Korio Miura com objetivo de reduzir a área de uma superfície segundo um padrão de dobragens que cria uma tesselação formada por paralelogramos. O origami Miura é uma estrutura utilizada inicialmente para dobragem de mapas e de painéis solares de satélites. Nesta etapa foi utilizado como suporte de referência o livro Origami Tessellations: Awe-Inspiring Geometric Designs (GJERDE, 2008).

Além da utilização de métodos de dobragem de papel como fonte de inspiração para a criação de um protótipo, também foi estudada a possibilidade do uso da deformação de materiais como meio para a geração de diferentes padrões geométricos. Neste caso, foi avaliada a alteração da forma em tecidos com propriedades elásticas.

Como a intenção era que o sistema associasse fatores ambientais à presença do usuário e à atividade que poderia estar sendo desenvolvida no espaço, optou-se por combinar a deformação destes materiais à ação de atuadores. Como resultado, a característica básica dos materiais inteligentes, de apresentarem uma "inteligência" interna, não foi absorvida ao longo da pesquisa.

Nesta etapa da investigação foram elaborados tanto modelos físicos, em diferentes materiais, quanto digitais, gerados em ambientes de modelagem paramétrica visual. No primeiro caso, os modelos foram criados com materiais simples, em um processo exploratório. Por exemplo, padrões geométricos elaborados por meio da dobragem de papel, segundo a técnica Miura Fold, foram separados e alterados, de modo a se compreender quais seriam os aspectos da forma que poderiam contemplar as características que se buscava no Cobogó responsivo. Em relação aos modelos paramétricos, estes foram implementados a partir do que foi verificado nos modelos físicos e, também, foram exploradas novas ideias.

Além de definir um padrão geométrico, tanto os modelos físicos quanto os paramétricos também foram elaborados com o objetivo de realizar testes preliminares e verificar as dificuldades que poderiam ser enfrentadas em relação à automatização do sistema. 


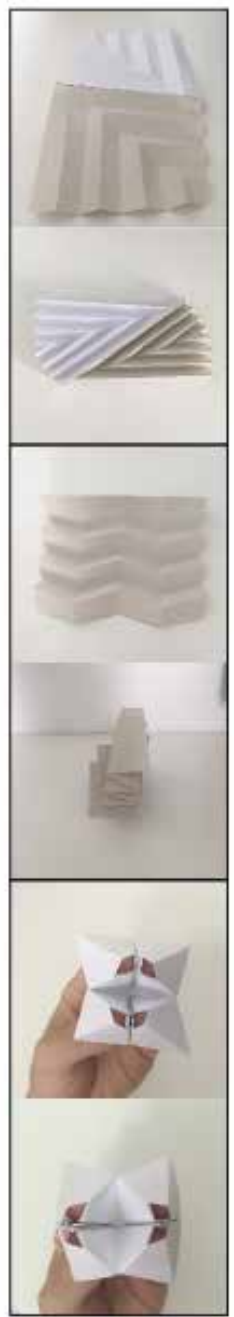

2
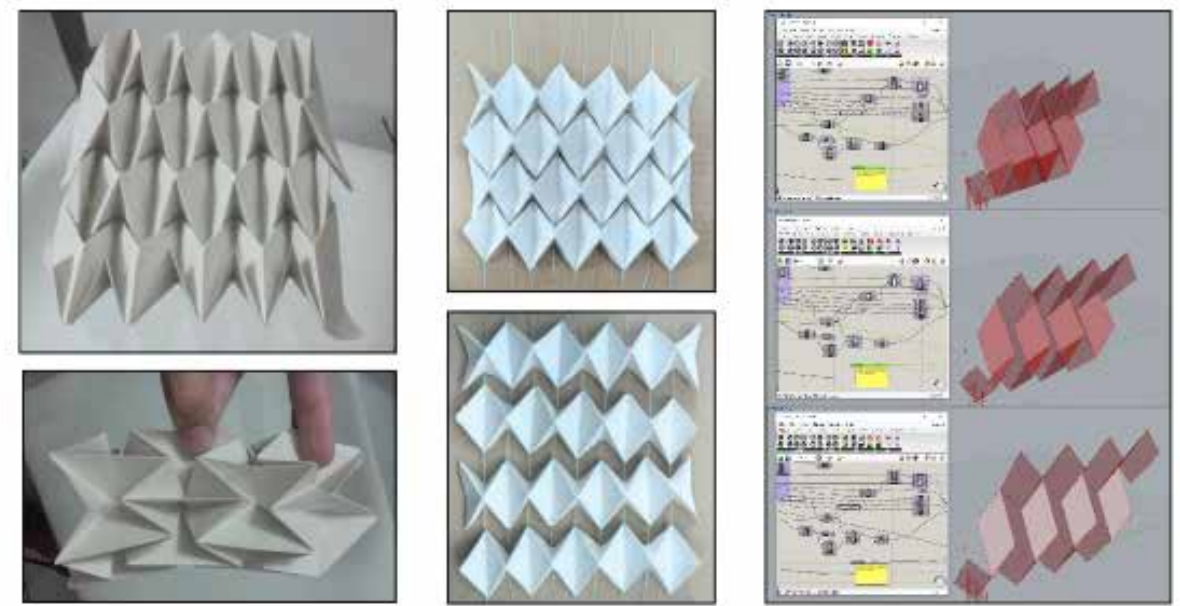

3
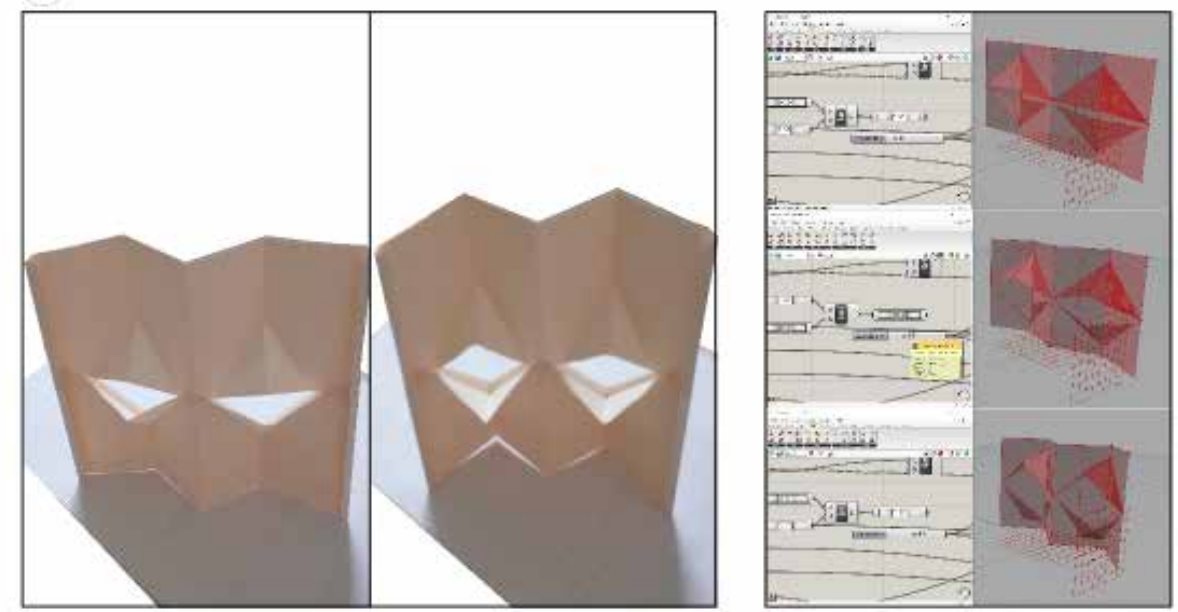

Como resultado, nesta etapa também se passou a investigar os diferentes tipos de atuadores e motores elétricos (servo motores, motores de passo e corrente contínua) que possibilitariam deslocar as partes dos protótipos estudados. Como parte do objetivo da pesquisa era buscar a redução de custos e evitar a dificuldade de aquisição de componentes, foi estudado, por exemplo, a utilização de motores de passo presentes em componentes eletrônicos (leitores de CD e DVD, drives de disquete, etc.) abandonados na própria Universidade Federal de Pernambuco e que podem ser encontrados na maioria das instituições públicas de ensino superior.

A partir dessa etapa da pesquisa optou-se por utilizar micro servo motores (HXT9001) como atuadores por estes serem de fácil aquisição, baixo custo e simples instalação. Apesar dos motores de passo estarem disponíveis na Universidade em equipamentos obsoletos, estes requerem um maior conhecimento de eletrônica para funcionarem de forma adequada e, a partir de motores de corrente contínua, não é possível controlar o giro do eixo de forma precisa, impossibilitando interromper o movimento em ângulos pré-definidos.
Figura 5: (1) Modelos executados por meio de dobragem de papel; (2) Modelo executado por meio da técnica de dobragem Miura fold, seu desmembramento para testes de movimentação e modelo paramétrico; (3) Outro exemplo de modelo gerado por dobragem e o respectivo modelo paramétrico. Fonte: Elaboração própria. 


\section{aplicativos de ventilação e illuminação}

Nesta etapa o objetivo era criar modelos paramétricos com a intenção de simular qual poderia ser o comportamento do protótipo físico em relação a mudança de diferentes parâmetros climáticos. As simulações foram realizadas visando compreender dois aspectos diferentes nos modelos. No primeiro, cada módulo foi implementado e estudado com o objetivo de avaliar como se daria a alteração da sua geometria levando em consideração intervalos numéricos similares aos dos parâmetros ambientais. Por exemplo, se a temperatura e a umidade aumentam em um ambiente, qual porcentagem da área deve abrir no sistema, permitindo assim o aumento da ventilação? Se a luminosidade diminui no ambiente interno, qual deverá ser a proporção de abertura para entrada de luz natural?

A outra abordagem envolveu o uso de diferentes plug-ins e ferramentas de simulação ambiental com o objetivo de compreender melhor quais aspectos poderiam ser trabalhados a partir do protótipo que estava sendo desenvolvido. Esta fase da pesquisa também foi realizada de modo exploratório, sendo que os diferentes aspectos ambientais não foram aprofundados. Por exemplo, o módulo de extensão Geco, para Grasshopper, foi utilizado para criar uma conexão com o aplicativo de análise de performance ambiental Autodesk Ecotect. A partir dele foi possível pré-visualizar a radiação solar que incidiria sobre as partes do modelo. Também, por meio do plug-in DIVA foi analisada a variação da intensidade luminosa e no aplicativo Autodesk Flow Design a alteração do fluxo de vento. Em relação à ventilação, o objetivo era verificar, de forma preliminar, a possibilidade de mudar o deslocamento do vento segundo as necessidades de cada ambiente. A Figura 6 mostra o modelo paramétrico e diferentes configurações do Cobogó, com o objetivo de redirecionar o fluxo de ar.

\section{Etapa 3 - Correlação entre sensores e modelos digitais}

A partir dos resultados obtidos na fase anterior, passou-se à etapa de implementação dos sensores utilizando-se uma plataforma de prototipagem eletrônica de hardware livre e de placa única. Ao invés de construir um protótipo físico, os testes foram realizados em ambiente digital, a partir do modelo paramétrico. Este processo permitiu testar o algoritmo que iria movimentar as partes do Cobogó antes mesmo de construir o protótipo físico. Inúmeras opções poderiam ter sido avaliadas por meio deste método, pois não há custo para alterar e gerar novos modelos. 0 que pode se tornar inviável quando se deseja construir um protótipo físico funcional.
1

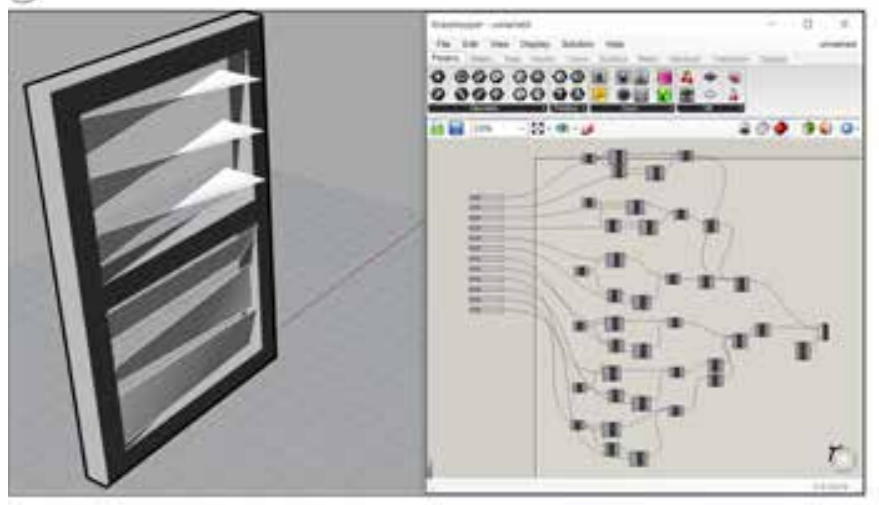

(2)

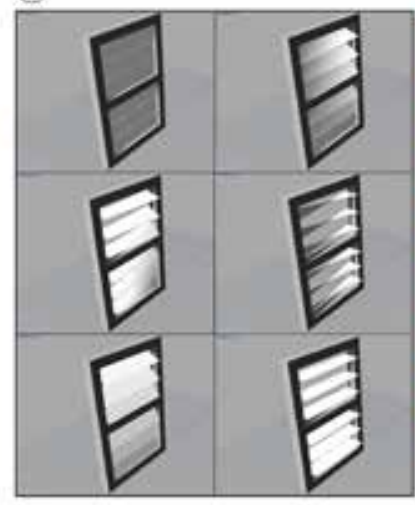

3

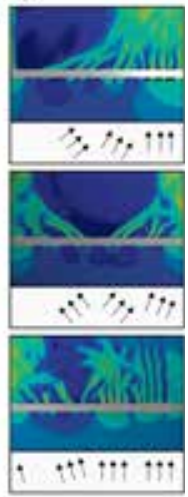




\begin{tabular}{|l|l|l|l|}
\hline Fase & Componente & Objetivo \\
\hline 1 & Arduino & Plataforma de prototipagem eletrônica & $\begin{array}{l}\text { Processa os dados coletados pelos } \\
\text { sensores }\end{array}$ \\
\hline 2 & Gobetwino & $\begin{array}{l}\text { Aplicativo que coleta ou envia dados por meio de } \\
\text { portas seriais. Outra possibilidade é a utilização da } \\
\text { biblioteca serial do próprio Processing. }\end{array}$ & $\begin{array}{l}\text { Utilizado como ponte entre o } \\
\text { Arduino e o ambiente Processing } \\
\text { IDE }\end{array}$ \\
\hline 4 & Processing IDE & $\begin{array}{l}\text { Linguagem de programação de código aberto e } \\
\text { ambiente de desenvolvimento integrado }\end{array}$ & $\begin{array}{l}\text { Utilizado para processar os dados } \\
\text { coletados pelo Gobetwino }\end{array}$ \\
\hline 5 & GHOWL & $\begin{array}{l}\text { Conjunto de componentes que estendem a habilidade } \\
\text { do Grasshopper de comunicar e trocar informações } \\
\text { com outras aplicações e dispositivos fisicos }\end{array}$ & $\begin{array}{l}\text { Coletar os dados processados pelo } \\
\text { Processing e direcioná-lo ao modelo } \\
\text { paramétrico }\end{array}$ \\
\hline
\end{tabular}

Fonte: elaboração própria.

Este pode ser um aspecto interessante, pois por meio deste processo é possível ensinar inúmeros conceitos aos estudantes, correlacionando o mundo real ao digital.

Para capturar as informações diretamente do ambiente foram instalados três sensores: o de temperatura com precisão calibrada de $1^{\circ} \mathrm{C}$ (LM35), o de umidade que abrange um intervalo de $20 \%$ a 50\% (DHT11) e o de luminosidade cuja resistência varia conforme a quantidade de luz (LDR). Estes foram conectados a uma placa de Arduino UNO, responsável por processar os dados coletados no ambiente e enviar ao modelo paramétrico. A sequência de aplicativos e ferramentas utilizadas é apresentada no Quadro 1. A Figura 7 mostra o sensor de temperatura sendo testado.

\section{Etapa 4 - Elaboração de protótipo físico funcional do modelo}

Apesar de diferentes modelos físicos e digitais terem sido desenvolvidos na primeira etapa da pesquisa, apenas um foi selecionado para a implementação em um protótipo físico funcional. Os modelos elaborados a partir da dobragem de papel apresentavam um padrão de movimentação das partes mais complexo, com deformações em relação aos eixos X, Y e Z. Como resultado, o protótipo final foi elaborado levando em consideração a deformação do material a partir movimentação causada por atuadores. A Figura 8 mostra a configuração final do protótipo. Nele, são movimentadas três fitas largas de poliéster posicionadas paralelamente, na horizontal. Cada uma de suas pontas é fixada a um servo motor acoplado em uma esquadria de alumínio de formato retangular, sendo que estas podem se mover separadamente, promovendo, por meio da torção, diferentes gradientes de circulação de ar e de entrada de luz no ambiente. Na mesma imagem diferentes possibilidades de composição da fachada também são apresentados.
Quadro 1: Quadro apresentando os aplicativos segundo a sequência de transferência dos dados até os modelos paramétricos. Fonte: elaboração própria.

Figura 7: Correlação entre os sensores e o modelo digital por meio de placa de prototipagem eletrônica. Fonte: Elaboração própria.

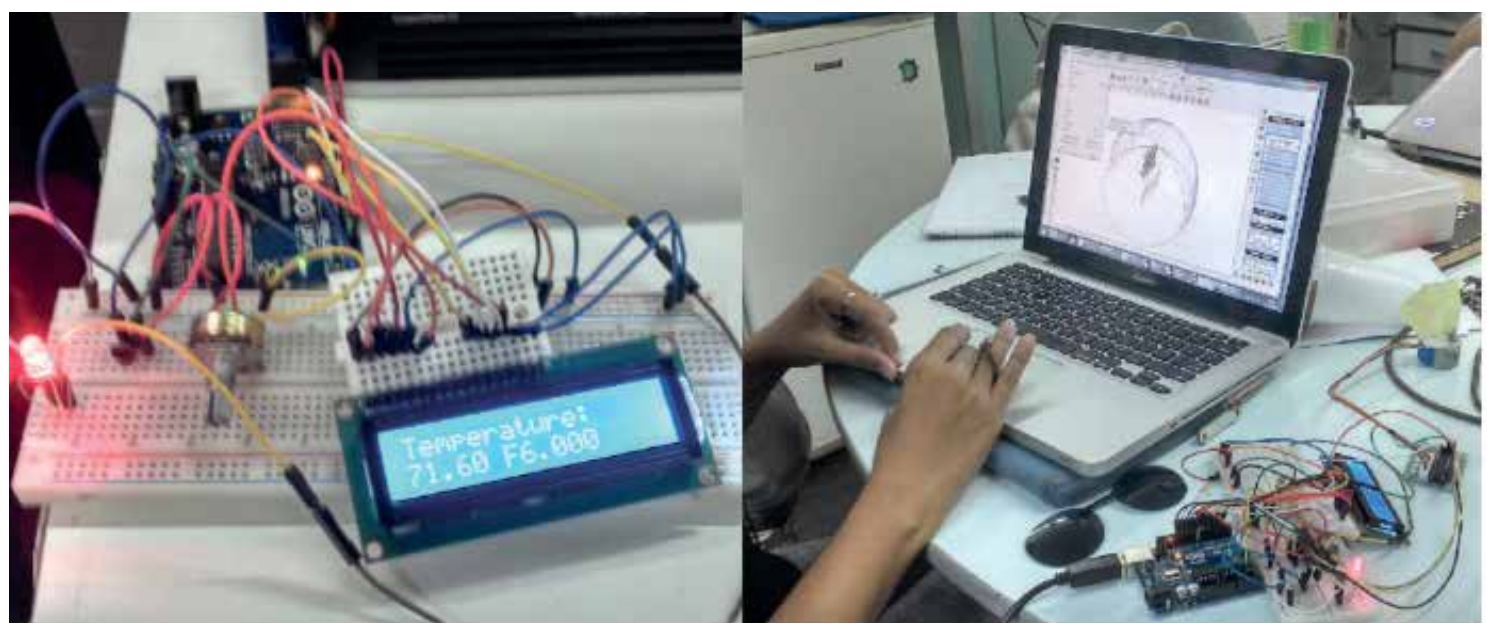



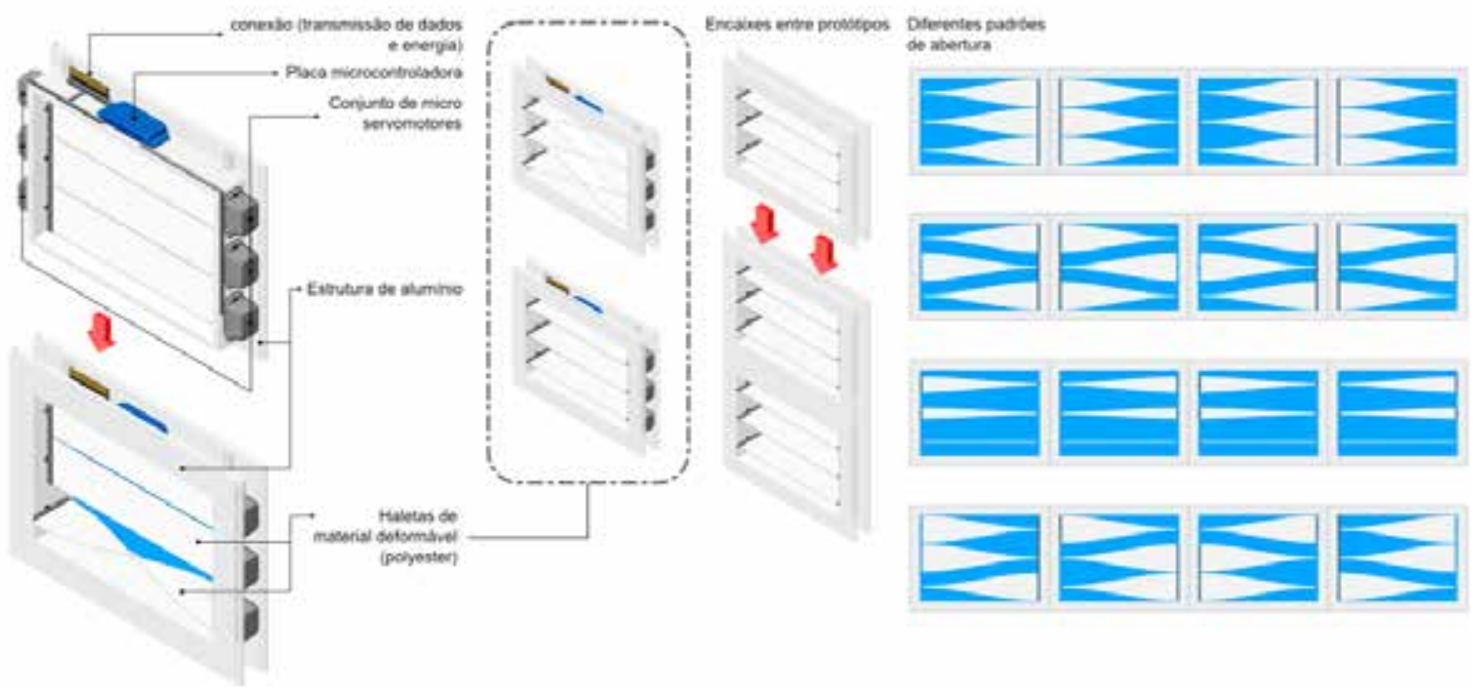

Figura 8: Esquema geral do protótipo. Fonte: Elaboração própria.

Figura 9: (1) Proto versão do sistema em um modelo funcional executado em papelão; (2) Vista frontal e inferior do protótipo físico funcional; (3) Diferentes posições pelo acionamento de sensores. Fonte: Elaboração própria.
A implementação do protótipo físico funcional foi realizado em duas etapas diferentes. Inicialmente, uma versão simplificada do sistema foi prototipada em um modelo de papelão (Figura 8), descartando assim o efeito da torção das fitas elásticas. Neste caso, o objetivo era realizar um teste inicial sem a confecção da esquadria de alumínio, prevendo-se assim futuros problemas. Em uma segunda etapa o protótipo final foi construído. A mesma figura apresenta este em funcionamento, com o mesmo código utilizado para controlar o sensor de temperatura e enviar os dados ao modelo digital. Como resultado, as respostas obtidas no mundo real foram muito semelhantes às que foram testadas na fase anterior. Portanto, realizar a ponte entre sensor físico, além de não ser um processo complexo, colaborou na compreensão do que iria ocorrer a partir da construção do protótipo.

\section{RESULTADOS}

Apesar de terem sido desenvolvidos vários modelos físicos e digitais, o protótipo físico final foi elaborado com materiais simples e com reduzida complexidade geométrica. Optou-se por esta estratégia devido a restrições em relação à obtenção de materiais e equipamentos adequados confecção do modelo e sua automação. Contudo, apesar do componente em si apresentar uma geometria simples, quando trabalhando em conjunto há uma grande possibilidade de composições pelos diferentes níveis de movimentação. As ilustrações apresentadas na Figura 7 mostram esta flexibilidade do sistema. Esta característica é comparável com a dos Cobogós tradicionais em que,

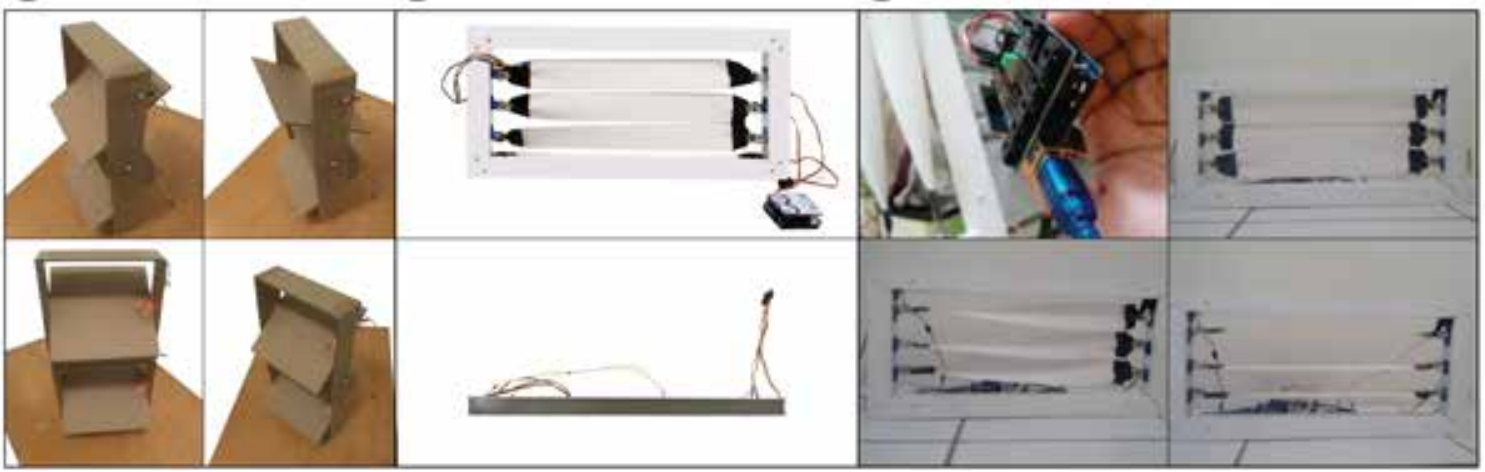


um elemento de geometria simples repetido em larga escala, gera um efeito compositivo em panos de fachada.

Outra característica que deve ser ressaltada é a flexibilidade de resposta que o uso de atuadores pode dar ao sistema. A partir deles e de diferentes sensores e estratégias é possível construir algoritmos que gerem movimentos pré-definidos, como resposta a estímulos ambientais ou em relação à presença de usuários. Por outro lado, apesar de depender de uma fonte de energia para funcionar, esta capacidade o torna um ótimo objeto de pesquisa e ensino. No primeiro caso, é viável desenvolver inúmeros algoritmos para o seu funcionamento. Já, no segundo caso, pode ser utilizado como instrumento para o ensino de conceitos simples de modelagem paramétrica, programação e computação física a estudantes de arquitetura e urbanismo.

\section{CONCLUSÕES}

A partir deste trabalho foi possível dominar, mesmo que parcialmente, uma série de ferramentas e o conhecimento necessário para criar protótipos tanto digitais quanto físicos de elementos de proteção de fachada. Ainda não há resultados sobre a eficiência do protótipo aqui apresentado, segundo os diferentes parâmetros ambientais. Este processo demanda um estudo para cada um dos diferentes aspectos. Por exemplo, em relação à possibilidade de se alterar a direção do vento em ambientes foi realizado um pequeno experimento. Contudo, para se concluir se de fato isto é possível é necessário realizar outros experimentos aprofundados, com diferentes tipos de modelos, tanto físico quanto digitais, e com auxílio de um especialista na área. Ou seja, o trabalho futuramente irá se desmembrar em outras pesquisas, aprofundando assim o estudo das fachadas responsivas.

O controle do ferramental utilizado nesta pesquisa também já possibilitou a realização de um curso de curta duração, sobre fachadas responsivas, na Universidade Federal de Pelotas. Utilizando parte das técnicas adotadas durante a pesquisa foi possível rapidamente gerar modelos paramétricos e, alguns destes, foram selecionados para serem implementados em protótipos físicos. O curso teve duração de três dias e os resultados são apresentados na Figura 9.
Figure 10: (1) Imagens durante o desenvolvimento de protótipos físicos funcionais. (2) Modelos paramétricos elaborados durante o workshop. Fonte: Elaboração própria.
(1)

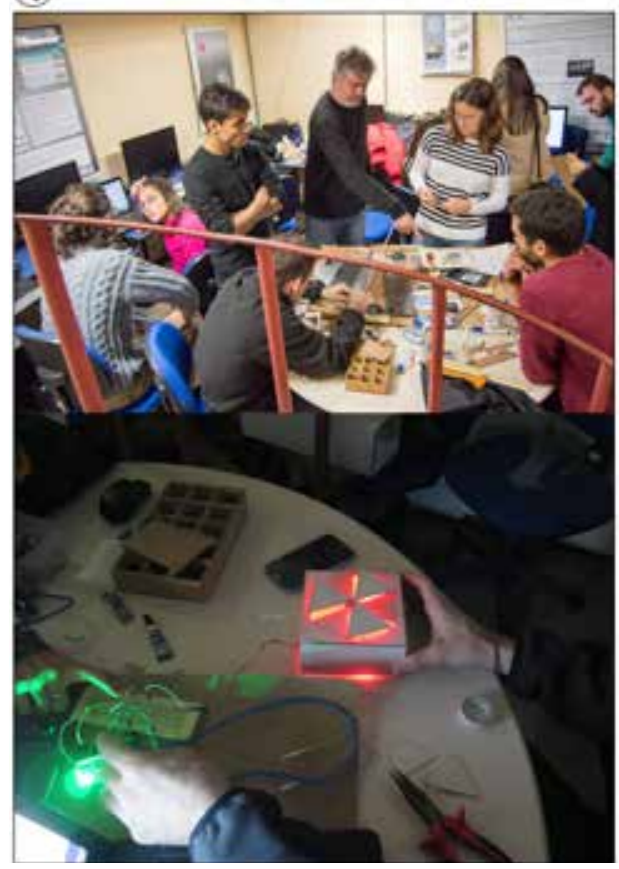

\section{(2)}

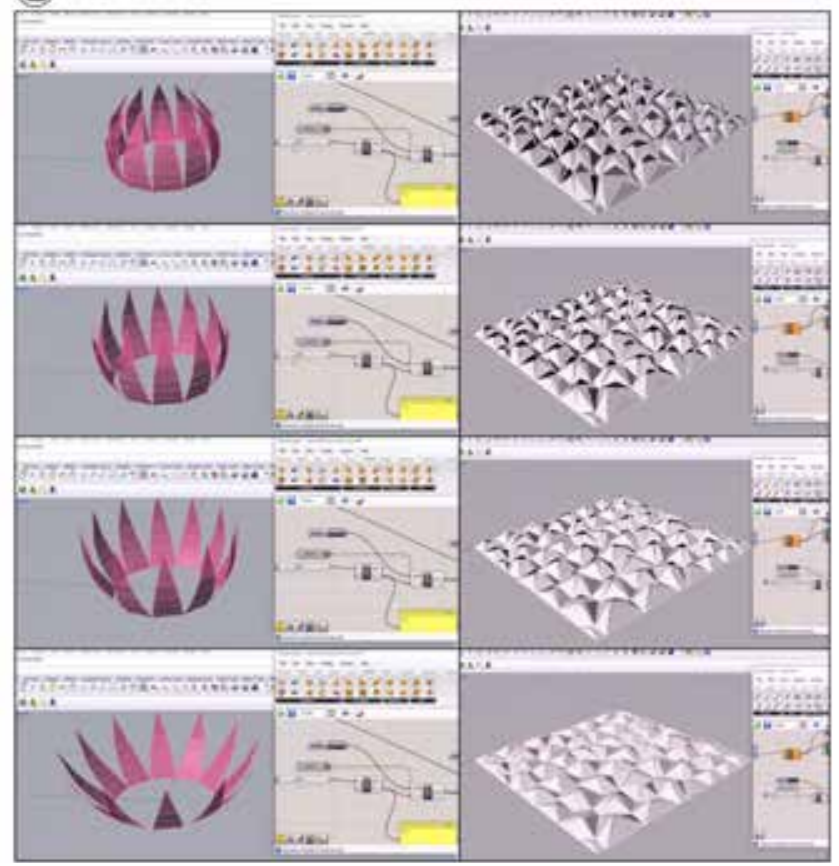




\section{AGRADECIMENTOS}

Agradecemos a Coordenadoria de Pessoal de Nível Superior (CAPES) pelo financiamento da pesquisa por meio de uma bolsa de iniciação científica.

\section{REFERÊNCIAS}

ACHTEN, Henri. One and Many: An Agent Perspective on Interactive Architecture source. Fonte: ACADIA 14: DESIGN AGENCY, 34, 2014, Proceedings of the 34th Annual Conference of the Association for Computer Aided Design in Architecture (ACADIA), Los Angeles, $\mathrm{p}$. 479-486.

ADDINGTON, Michelle; SCHODEK, Daniel. Smart materials and new technologies. Oxford: Architectural Press, 2005.

BARROS, H.; LOMBARDO, M. Zoneamento climático urbano da cidade do Recife: uma contribuição ao planejamento urbano. Revista GEOUSP: Espaço e Tempo, São Paulo: n. 33, p. 187-197, 2013.

D’ALECON, Renato. Fachadas transparentes: sistemas activos y passivos. Cuadernillo de la técnica, Santiago, n. 84, p. 1-5, Ago. 2013.

DEWIDAR, K.; MOHAMED, N.; ASHOUR, Y. Living Skins: A New Concept of Self Active Building Envelope Regulating Systems. In: SB13 DUBAI, 1, 2013, Dubai, Living Skins: A New Concept of Self Active Building Envelope Regulating Systems, 2013. Disponivel em: <https:// www.irbnet.de/daten/iconda/CIB DC26849.pdf> Acesso em: Ago. 2014

DYE, Daniel. Chinese Lattice Designs. Nova York: Dower Publications Inc., 1974

FORTMEYER, Russell; LINN, Charles D. Kinetic architecture: designs for active envelopes. Mulgrave: The Images Publishing Group, 2014.

FRANCO, José. As Torres Al Bahar e sua fachada sensível, por Aedas Architects. Revista on-line Archdaily, 28 Jan. 2013. Disponível em: < http://www. archdaily.com.br/br/01-93779/as-torresal-bahar-e-sua-fachada-sensivel-poraedas-architects>. Acesso em: 20 Maio 2014.

FREITAS, Ruskin. Entre mitos e limites: as possibilidades do adensamento construtivo face à qualidade de vida no meio urbano. Recife: EDUFPE, 2008.

GJERDE, Eric. Origami Tessellations:
Awe-Inspiring Geometric Designs. Massachusetts: A K Peters Press, 2008.

GUTIERREZ, Grace; LABAKI, Lucila. Considerações sobre o brise-soleil na arquitetura moderna Brasileira. In: VIII ENCONTRO NACIONAL E IV ENCONTRO LATINO-AMERICANO SOBRE CONFORTO NO AMBIENTE CONSTRUÍDO, 2005, Maceió. Anais do ENCAC ELACAC, 2005, Maceió: ANTAC, v. 1, p. 874-882

Instituto Nacional de Meteorologia (INMET). Normais climatológicas do Brasil 1961-1990. Disponível em: <http://www. inmet.gov.br/portal/index.php?r=clima/ normaisclimatologicas> Acesso em: Jan. 2014.

KLOOSTER, Thorsten. Smart Surfaces and their Application in Architecture and Design. Berlin: Birkhauser T. press, 2009.

LIFT ARCHITECTS. The air flow(er). Disponivel em:<http://www.liftarchitects. com/\#/air-flower> Acesso em: Jul. 2016.

MARCON, Naiane. Escritórios do Conselho de Melbourne 2 (CH2) / Designlnc. Revista on-line Archdaily, 5 Ago. 2013. Disponível em: < http://www.archdaily.com. br/br/01-132298/escritorios-do-conselho-de-melbourne-2-ch2-slash-designinc>. Acesso em: 26 Maio 2014.

NEGROPONTE, Nicholas. Soft Architecture Machines. Cambridge: MIT Press, 1975.

NISHIYAMA, Yutaka. Miura Folding: Applying Origami to Space Exploration. International Journal of Pure and Applied Mathematics.v. 79, n. 2, p. 269-279, Abr. 2012.

OLIVEIRA, N. Superfícies abstratas: o elemento cerâmico como textura na arquitetura moderna brasileira In: IV SEMINÁRIO DOCOMOMO SUL: Pedra, barro e metal - Norma e licença na arquitetura moderna do cone sul americano, 1930/70, 2013.

SDU Campus Kolding / Henning Larsen Architects. Revista on-line ArchdaiIy, 30 Jan. 2015. Disponível em: <http:// www.archdaily.com/590576/sdu-cam- 
pus-kolding-henning-larsen-architects>. Acesso em: 30 Maio 2014.

SUNG, Doris. Prototyping a Self-Ventilating Building Skin with Smart Thermobimetals. Disponível em: <http://www.aia. org/aiaucmp/groups/aia/documents/ pdf/aiab092636.pdf>. Acesso em: Ago. 2014

SOUZA, Heloisa. O conforto ambiental na arquitetura colonial brasileira: heranças muçulmanas. Architecton: revista de arquitetura e urbanismo. v.2, n.2, p. 41-54, 2012.

STINY, G. Ice-ray: a note on Chinese lattice designs. Environment and Planning
B: Planning and Design, v. 4, n. 1, p. 8998, 1977.

TALIB, Kaizer. Review of climatic design concepts and details in traditional architecture in various climatic zones - Saudi Arabia. In: INTERNATIONAL AND PASSIVE LOW ENERGY ARCHITECTURE CONFERENCE, 1983, Creta. Proceedings of the Second International PLEA Conference. Oxford: Pergamon press, 1983, p. 233-245.

VIEIRA, Antenor; BORBA, Cristiano, RODRIGUES, Josivan. Cobogó de Pernambuco. Recife: J. Rodrigues, 2012.

\section{Corrêspondência:}

Carlos Eduardo Verzola Vaz

cevv00@gmail.com

Joana Pack Melo Sousa

joanapacksousa@gmail.com

Hugo Rodrigues de Souza Pinto

hugordsp@gmail.com

Adriano Rodrigo Barreto Cardoso

adrianoarbc@gmail.com

Natalia Queiroz

nataliaqueiroz.arq@gmail.com 